\title{
Chronic subdural hematoma as a complication of medicinal leech therapy
}

\author{
Nuri Serdar Baş $M D$, Azmi Tufan $M D$ \\ Department of Neurosurgery, Bagcilar Training and Research Hospital, University of Health Science, \\ Istanbul, Turkey
}

\begin{abstract}
Applications related to the use of leeches in medical therapies date back for centuries. We present here a case of self-administered leech application for chronic low back pain who subsequently developed complication of chronic subdural hematoma. We are not aware of similar report in the literature. This was a 34-year-old man who was admitted to our Emergency Department with headache, right side numbness, and intermittent difficulty in speaking. During the neurological examination, it was observed that the patient had difficulty in speaking and pronouncing words intermittently while taking his medical history. Motor examination was normal. The patient did not report any recent trauma. There was no known history of systemic or hereditary disease, drug or substance abuse. Cranial CT and MR imaging showed a left frontoparietal chronic subdural hematoma. Further history was obtained that leech was applied to the patient for low back pain in the last 45 days, two times at 15 days intervals. The patient's drowsiness and speech difficulties improved after the surgical operation. On one month follow-up, neurological examinations were normal. Our patient shows that leech therapy can be complicated by subdural hematoma.
\end{abstract}

Keyword: Chronic subdural hematoma, leech therapy, hirudotherapy, complementary medicine practices, traditional medicine practices

\section{INTRODUCTION}

The use of leeches in medical therapies date back for centuries. ${ }^{1}$ Leeches provide medicinal effects and benefits by sucking out blood and delivering many bioactive substances to the tissue they bite through their secretions. These bioactive substances have many biological and pharmacological properties, notably antiaggregant and anticoagulant effects. ${ }^{2}$ Upon the development of medical pharmacology over time, the use of medicinal leech has decreased. However, with the growing importance of traditional medicine, the number of people applying this treatment in Turkey have increased. In this report, we present a case of self-administered leech application for treatment of chronic low back pain, who subsequently developed chronic subdural hematoma.

\section{CASE REPORT}

This was a 34-year-old man who was admitted to our Emergency Department with headache, right side numbness, and intermittent difficulty in speaking. During the examination, it was observed that he had minimal right hemihypoesthesia, and difficulty in speaking and pronouncing words intermittently while taking his medical history. Motor examination was normal. The patient did not report any recent history of trauma. There was no known history of systemic or hereditary disease, drug or substance abuse. He stated that he had panic attack and was diagnosed with lumbar disc herniation 5 years earlier. Cranial CT and MR imaging was performed which showed a left frontoparietal chronic subdural hematoma (Figure 1,2).

Upon a more detailed examination, numerous healing skin lesions at various stages were detected on the low back (Figure 3). When the patient was asked about these lesions, he mentioned that leech was applied for treating low back pain in the last 45 days, two times at 15 days intervals. Before the leech treatments, the patient did not have symptoms of headaches, numbness, and speech difficulties. Headache started right after the second leech application. About 15 days after the headache ( 15 days before admission to the

Address correspondence to: Nuri Serdar Baş, University of Health Science, Bagcilar Training and Research Hospital, Neurosurgery Department, Dr. Sadık Ahmet Cad. Bagcilar, 34200, Istanbul, Turkey. Tel: +90 5326060803, Email: nserdarbas@ yahoo.com.tr

Date of Submission: 20 April 2021; Date of Acceptance: 8 June 2021

https://doi.org/10.54029/2021ief 


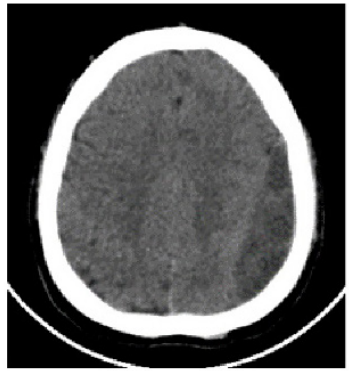

Figure 1: Preoperative axial CT, left parietal chronic subdural hematoma.

hospital), he started to have difficulty in speaking. A few days before he was admitted to the hospital, numbness began on his right side. After the leech therapy, there were no other signs of bleeding tendency such as gingival bleeding and / or bruises. There was no history of bleeding tendency or other relevant family history. When he was first examined in the hospital, there was no bruise on his skin. He added that there was no bruise during and after the leech treatments. There was no abnormalities in the systemic and hematological investigations performed. The Prothrombin Time (PT), active Partial Thromboplastin Time (aPTT), International Normalized Ratio (INR) were all within normal limits.

It was thought that subdural hematoma developed gradually over time, secondary to antiaggregant and anticoagulant bioactive substances, which were mixed into the blood 2 times during long-lasting leech application. The hematoma was drained under general anesthesia with single burr-hole drainage. The patient's drowsiness and speech difficulties disappeared after the operation. On follow up at one week and one month, neurological examinations were normal, and the patient had no further complaint. The repeat cranial CT imaging performed in one month showed that the subdural hematoma has completely resolved (Figure 4).

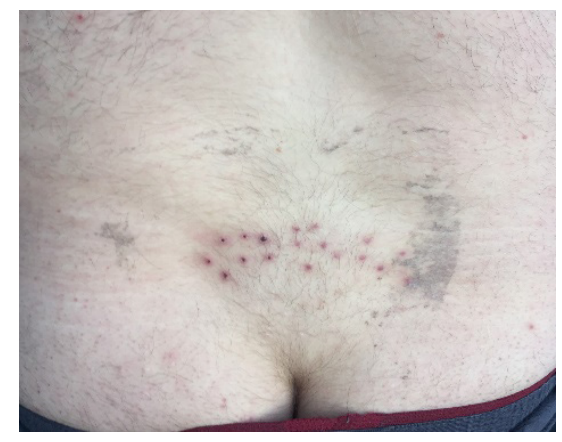

Figure 3: Leech bite marks in the lumbar region of the patient (at different stages)

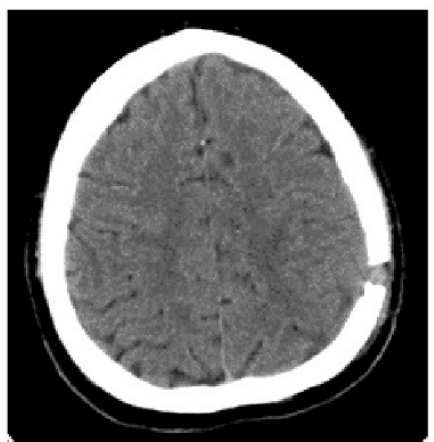

Figure 4: Postoperative axial CT brain after one month showing Burr hole and the subdural hematoma has completely disappeared.

\section{DISCUSSION}

Treatment with the use of medicinal leech is called hirudotherapy. This treatment practice dates to BC. The first written records can be seen on the wall paintings in ancient Egyptian Pharaoh's tombs. There are also articles on the medicinal use of leech in Chinese, Sanskrit, Persian, Arabic, and Roman literature. Ibni Sina's renowned book, "The Canon of Medicine" also includes pages about leech therapy. ${ }^{1,3}$ The term of hirudo medicinalis was used for the first time by
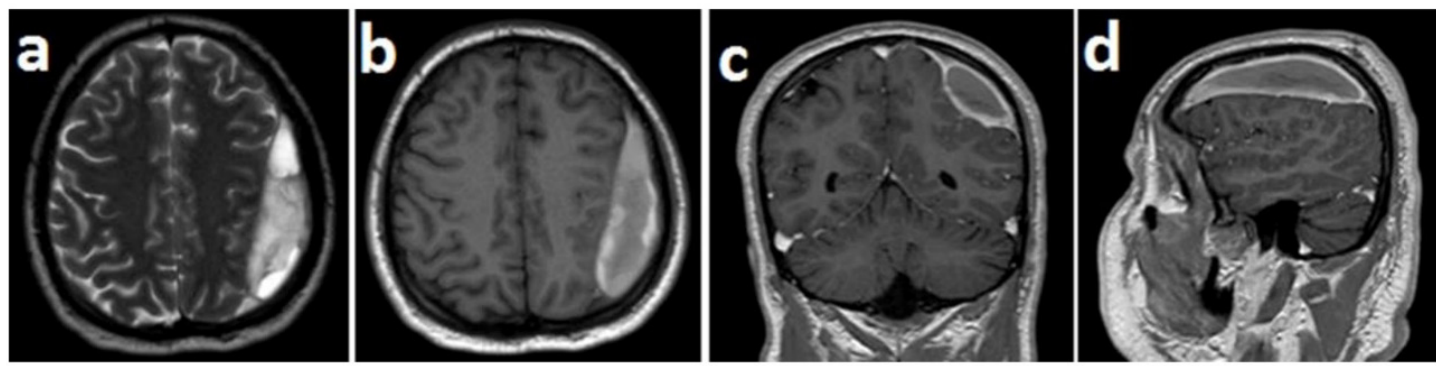

Figure 2: Preoperative MRI (a. T2 Axial, b. T1 Axial, c. Coronal, d. Sagittal), left parietal chronic subdural hematoma. 
the Swedish botanist Linnaeus (Carl von Linné, 1707-1778). ${ }^{1}$ The discovery of an anticoagulant substance, which is called hirudine in leech secretions by Haycraft was made in $1884 .{ }^{4}$ This substance was genetically engineered in 1986 as a potent anticoagulant. ${ }^{1}$

It was said that leech therapy mainly consisted of two effects. First, while the leech bites the skin of the host, it injects salivary gland secretion into the wound. This provides painless blood suction by creating analgesic and anticoagulant effects. Second, with other secretions, the blood is kept in a liquid form. ${ }^{5}$

Extensive research on leech saliva recently revealed the presence of various bioactive peptides and proteins including antithrombin (hirudin, bufrudin), antiplatelet (calin, saratin), factor Xa inhibitors (lefaxin), antibacterial (theromacin, theromyzin), bdellins, hyaluronidase, acetylcholine, histamine-like substances, eglin, hirustasin, collagenase, and many others..$^{2,5,6}$ These different bioactive substances in leech secretion show different effects in the host body such as anticoagulant, fibrinolytic, anti-inflammatory, analgesic, vasodilator, antimicrobial, increasing interstitial viscosity, and inhibition of some enzymes. It has also been shown that this secretion contains broad-spectrum antibacterial peptides. ${ }^{7}$ Hence, leech secretion has been reported to be used in inflammatory conditions, thrombophlebitis, thrombosis, some cardiovascular diseases such as thrombosis, varicose vein and embolism, hemorrhoids, hematoma, painful diseases of the spine, rheumatological diseases such as arthrosis, osteoarthritis, periarthritis and rheumatoid arthritis, the external auditory canal and chronic ear infections, eye diseases such as traumatic injury and inflammation, dental diseases such as gingivitis, periodontitis, and gingival edema, skin diseases such as dermatitis, psoriasis, and chronic ulcer, respiratory diseases such as asthma and acute rhinopharyngitis, male and female infertility, mastitis-like breast diseases, anti-metastatic cancer treatments, in plastic and reconstructive surgery for removal of venous congestion in replantations of flap, tissue and limb (penis, finger). ${ }^{2,6}$ Its indication for chronic low back pain, which is the reason for our patient to apply leech therapy has also been reported. ${ }^{8}$

Leech therapy is not without complications. Complications can be classified under five main groups as infection (51\%), allergy (21\%), prolonged bleeding $(15 \%)$, migration $(8 \%)$, and others (5\%). ${ }^{9}$ The most common complication is infection, and it accounts for nearly half of the complications. Generally, the infective agent is Aeromonas hydrophila. It can be in the form of local wound infection or in the form of pneumonia, septicemia, gastroenteritis, or even meningitis. Contamination of various blood-borne infections such as AIDS and viral hepatitis may also occur. Besides, local, or widespread hypersensitivity may occur, including itching, blistering, ulcerative necrosis, and tissue damage caused by the presence of some toxins in the leech saliva. Anemia due to prolonged bleeding-related blood loss has also been reported. ${ }^{6.9}$ More seriously, it may lead to hemorrhagic shock and death..$^{10,11}$ The development of subdural hematoma in the case we have presented is also a life-threatening complication.

In cases with acute and severe bleeding after medical leech application, PT, aPTT and INR values may be remarkably high in the early period. However, cases in which these values were normal during the acute bleeding period have also been reported..$^{11}$ Deshmukh et al. reported that there was no change in prothrombin values. ${ }^{12}$ Thus, values of PT, aPTT, and INR may be high or normal. Similarly, in our case, these values were within normal limits, as the time interval from the second leech treatment was almost one month.

In the review of literature, no similar case has been reported previously. We believe this is the first patient to be reported of leech therapy complicated by chronic subdural hematoma.

In conclusion, hirudotherapy is increasingly used as conventional and complementary medicine practice in Turkey. Its use in modern medicine includes plastic and reconstructive surgeryrelated implantations of flap, tissue, and limb. The widespread use of this practice increases the complication seen. It should be kept in mind that leech therapy could lead to acute or chronic bleeding in various tissues and organs. It should be looked for in cases of hemorrhage and hematoma in young patients whose cause is not clear.

\section{DISCLOSURE}

Consent to participate/Consent for publication: Written informed consent was obtained from the patient for publication of this case report and any accompanying images.

Financial support: None

Conflict of interest: Nothing to declare. 


\section{REFERENCES}

1. Whitaker IS, Rao J, Izadi D, Butler PE. Historical Article: Hirudo medicinalis: ancient origins of, and trends in the use of medicinal leeches throughout history. Br J Oral Maxillofac Surg 2004;42(2):133-7,

2. Abdualkader AM, Ghawi AM, Alaama M, Awang M, Merzouk A. Leech therapeutic applications. Indian J Pharm Sci 2013;75(2):127-37.

3. Munshi Y,Ara I, Rafique H,Ahmad Z. Leeching in the history-a review. Pak J Biol Sci 2008;11(13):1650-3.

4. Haycraft JB. On the action of a secretion obtained from the medicinal leech on the coagulation of the blood. Proc R Soc Lond 1883;36:478-87.

5. Baskova IP, Zavalova LL. Proteinase inhibitors from the medicinal leech Hirudo medicinalis. Biochemistry (Mosc) 2001;66(7):703-14.

6. Das BK.An overview on hirudotherapy/leech therapy. Ind Res J Pharm Sci 2014;1(1):33-45.

7. Abdualkader AM, Merzouk A, Ghawi AM, Alaama M. Some biological activities of Malaysian leech saliva extract. IIUM Engineering Journal 2011;12:4.

8. Hohmann CD, Stange R, Steckhan N, et al. The effectiveness of leech therapy in chronic low back pain. Dtsch Arztebl Int 2018;115(47):785-92.

9. Pourrahimi M, Abdi M, Ghods R. Complications of leech therapy. Avicenna J Phytomed 2020;10(3):22234.

10. Güven R. Treatment of a patient in hemorrhagic shock due to leech bite with tranexamic acid. Am J Emerg Med 2016;34(11):2253.e3-2253.e4.

11. Kose A,Zengin S, Kose B, et al.Leech bites: massive bleeding, coagulation profile disorders, and severe anemia. Am J Emerg Med 2008;26(9):1067.e3-6.

12. Deshmukh SS, Varshney SS, Wankhede GN. Haematological alterations in human blood after leech application. International Journal Molecular Genetic 2012; 2(1):1-10. 